\title{
A personalidade pura
}

\author{
Emmanuel Cattin \\ Universidade Blaise Pascal - Clermont-Ferrand - França \\ najoski@orange.fr
}

resumo 0 presente trabalho é uma contribuição ao estudo do sentido da « personalidade pura », que surge ao final da Ciência de Lógica de Hegel, e que é ali o nome correto e último do « Conceito ». Com esse nome, Hegel pretende designar a afirmação da liberdade em sua identida de com a negativida de absoluta. Pa ra esclarecer esse ponto, será preciso, primeiro, explicar o sentido hegeliano de pessoa no campo do espírito objetivo, onde ela é alçada, na figura do imperador, à condição de « pessoa absoluta » (Fenomenologia do Espírito). No entanto, para além da rigidez desta última, a pessoa hegeliana é o nome do sujeito que decide. Tal decisão é pensada por Hegel como uma criação, a personalidade é precisamente a identidade da vontade e da inteligência, e é possível então passar da sua aparência objetiva à decisão da Id éia absoluta em sua própria afirmação como conhe cimento absoluto, isto é, à identidade he geliana da verda de substanc ial e do sujeito pessoal. palavras-chave Personalidade pura; sujeito; negatividade; Hegel; Ciência da Lógica

Clermont, 28 de setembro de 2006.

Ao final da Doutrina do Conceito de 1816, quando o liv ro ou, antes, o próprio caráter lógico, o conteúdo do livro, se condensa na profundidade, na densidade pura da Idéia absoluta que forma o conteúdo total da filosofia - conteúdo agora tornado plena e totalmente para si como método, como forma dialética pura -, Hegel escreve o seguinte: "Die höchste, zugeschärfteste Spitze ist die reine Persönlichkeit, die allein durch die absolute Dialektik, die ihre Natur ist, ebensosehr alles in sich befasst und hält,

Recebido em 20 de dezembro de 2007. Aceito em 20 de janeiro de 2008.

Tradução: Márcio Suzuki

doispontos, Curitiba, São Carlos, vol. 5, n. 1, p.139-152, abril, 2008 


\section{0}

weil sie sich zum Freisten macht - zur Einfachheit, welche die erste Unmittelbarkeit und Allgemeinheit ist". "O pico mais alto, o mais agudo, é a personalidade pura, que exclusivamente, em virtude da dialética absoluta que é sua natureza, ao mesmo tempo apreende e mantém tudo em si, porque faz de si o que há de mais livre, a simplicidade que é a primeira imediatez e universalidade"1. Assim, ao final - mas um final justamente enquanto retorno do início, enquanto simplicidade final em que o inicial vem se concentrar e intensificar guardando todo o caminho de seu desenvolvimento, enquanto pico mais pontiagudo, mais livre, isto é, absoluto do Sentido -, é precisamente pelo conceito de personalidade que se pensa o que é conceito, aquilo ou, talvez se devesse dizer, aquele que ele é, no pleno desenvolvimento de si como Idéia lógica absoluta. Com isso, a Persönlidhkeit é a última palavra do sistema hegeliano, se se trata mesmo ali da palavra do método, e se não há nenhuma diferença entre método e sistema,já que, em virtude de sua absolutez, o método absoluto "se alarga" por si mesmo num sistema, e o conteúdo "faz parte" da forma absoluta (HEGEL, 1994, p. 300). O sistema hegeliano - tal é a afirmação diretora aqui, e que será preciso esclarecer - é o sistema da personalidade pura. Noutras palavras, uma vez que a própria Idéia absoluta, em sua imediatez que regressa a si, é "ser", "vida que não passa" (unvergängliches Leben) e "verdade que sabe de si" (sich wissende Wahrheit), a afirmação hegeliana fundamental, que não seria sem dúvida impossível, de uma maneira surp reendente apenas em aparência, colocar lado a lado de uma grande afirmação kierkegaardiana, ainda que esta seja dirigida contra ela ${ }^{2}$, é a seguinte: A personalidade é a verdade. Mas resta ainda compreender uma afirmação tão forte e, antes de mais nada, nela, o sentido hegeliano de "personalidade", pela qual se entende, como é já possível de precisá-lo antes de qualquer consideração, a totalidade finalmente reagrupada em si - o próprio todo que se simplifica e se reafirma num Si. Mais exato talvez seja dizer: é menos o todo que é um Si, e antes - pois tal é a verdade desse ser, o ser-si - o Si que, em sua negatividade absoluta, possui tudo em si mesmo. Todo o ser do si reside precisamente neste enigmático sich zum Freisten machen, "se tornar o mais livre" ou melhor "fazer de si o mais livre”, que é, em sua essência, a afirmação de si do mais livre como sendo o mais livre, auto-afirmação na qual consiste inteiramente o Mais livre ele mesmo. A "personalidade" que nos propomos compreender aqui é esse 
sich zum Freisten machen, que terá por natureza a "dialética absoluta", assim exposta no momento final da Lógica. Que a dialética em seu caráter absoluto, que não é assim somente a negatividade, mas a negatividade ela mesma absoluta, o negativo do negativo, dê bem exatamente aqui o sentido da pessoa enquanto momento, não enquanto momento apenas subjetivo, como num fazer ou agir unilateral, numa conduta da subjetividade, mas um momento objetivamente espiritual ou momento objetivo da vida da subjetividade enquanto espírito, Hegel o escreve expressamente quanto se trata da questão da negatividade como Wendungspunkt [ponto de inflexão] do movimento do conceito: "O segundo negativo, o negativo do negativo, ao qual chegamos, é esse suprimir da contradição, mas ele não é, tampouco quanto o é a contradição, o fazer de uma reflexão exterior,mas é o momento mais interior, mais objetivo da vida e do espírito, pelo qual há um sujeito, uma pessoa, um Livre (Freies)" (HEGEL, 1994, Die Lehre vom Begriff, pp. 296-297; tr. p. 382). É, pois, definitivamente a mesma coisa pensar um sistema dialético, ou sistema da negatividade absoluta, e um sistema da subjetividade como sistema da pessoa pura ou sistema da liberdade, desde que se precise que uma tal subjetividade não se põe senão em virtude do mais objetivo ou do "mais interior", do mais necessário e do mais interior do espírito ("natureza" dialética, escreve Hegel) - a negatividade absoluta. Tal sistema da personalidade terá assim, em seu coração, a negatividade absoluta da segunda Aufhebung, do redobro da negação ou da relação a si desta, mediante a qual a contradição se suprime na afirmação espiritual total, isto é, livre, uma vez que o evento da personalidade pura repousa inteiramente sobre o Wendungspunkt que é o extremo ou o absoluto do negativo.

Entretanto, devemos primeiro compreender o que é uma pessoa e, tendo isso em vista, é para a Filosofia do Espírito que devemos nos voltar. Essa indicação nos é, de resto, dada pelo próprio Hegel quando, já na sua primeira abordagem da Idéia absoluta, ele se ocupa em afastar a "alma" ao pensar aquilo que é o conceito (nicht nur Seele), preferindo a ela "o conceito subjetivo livre que é para si e tem, por conseguinte, a personalidade". Num inciso, ele comenta bastante precisamente o sentido da Persönlichkeit.trata-se ali do "conceito prático, determinado em si e para si, objetivo, que é, enquanto pessoa, subjetiudade impenetrável (undurchdringliche), atômica (atome)." (HEGEL, 1994, Die Lehre vom Begriff,p. 284; 


\section{2}

tr., p. 368). Antes de mais nada é da mais alta importância observar que um conceito por si mesmo prático, re fe rente à esfera do espírito objetivo (que por conseguinte já ultrapassou enquanto tal a unilateralidade da mera subjetividade prática), fornece aqui exatamente o sentido da absolutez especulativa da Idéia lógica no momento em que ela se reagrupa totalmente em si mesma numa simplicidade e universalidade finais. É pois antes de mais nada a esse conceito prático do espírito objetivo que convém voltar, inclusive compreendido em sua unilateralidade espiritual, já que sua imediatidade mesma é aquilo que volta ao fim como simplicidade mais densa, mais profunda, mais liv re, para pensar a essência da Idéia absoluta.

A pessoa é o primeiro momento da objetividade do espírito, quando a vontade livre é vontade livre para si, vontade que sabe de si, ou identidade da vontade e da inteligência, singularidade universal que é a "própria liberdade", escreve Hegel (1988, Filosofia do Espírito, \401, p. 147). É preciso destacar que, em sua unificação da subjetividade e da objetividade mediante a supressão de si do espírito subjetivo ("Suprimiram-se o formalismo, a contingência e a subjetividade de sua atividade prática", notava Hegel ao fim do \401), enquanto Idéia que é para si, a pessoa já é o "conceito do espírito absoluto" (\$ 402). Mas ela não é justamente senão o seu conceito, e o saber de si que a constitui como subjetividade não existe no entanto nela senão como momento objetivo do espírito, ou momento inicial, que tem nele uma proveniência subjetiva, a partir da vida objetiva deste. A pessoa não é, ao final das contas, o sujeito, mas o sujeito objetivo, o sujeito que resulta da autonegação da subjetividade prática meramente contingente. $\mathrm{O}$ conceito de personalidade, tanto na Filosofia enciclopédica do espírito quanto nos Princípios da Filosofia do Direito, d eve ser compreendido a partir dessa proveniência. Observemos mais de perto o seu desenvolvimento espiritual.

A liberdade é primeiro a pura e simples relação a si da vontade singular. Uma tal vontade singular - a "vontade no interior de si singular de um sujeito" (HEGEL, 1998, \38, p. 125) - é primeiro sua própria relação negativa à "realidade", assim como sua efetividade é uma tal relação consigo. Sua universalidade é, pois, a de uma singularidade consciente de si, que é, ela mesma, pura relação a si mesma. Person ou persönlichkeit trazem claramente em si mesmos, em Hegel, uma afirmação de si, isto é, 
um puro Eu sou sem conteúdo, a auto-afirmação abstrata da liberdade, o Eu sou como Eu sou eu, Eu sou um Si, ou Eu sou infinito, Eu sou livre. Nos Princípios da Filosofia do Direito, Hegel dá a versão desenvolvida de tal auto-afirmação universal da singularidade enquanto pessoa: "Eu sou, enquanto este-aqui, uma pessoa perfeitamente determinada e finita sob todos os aspectos (em seu arbítrio, em seu impulso e seu desejo interiores, assim como também do ponto de vista de seu ser-aí exterior imediato), embora seja simplesmente pura relação à mim e tenha, dessa maneira, na finitude, saber de mim como do infinito, do universal e do livre." (HEGEL, 1998, \35, p. 126). O Eu é sempre um este-aqui, mas a pessoa que ele é, ou antes que se afirma enquanto $E u$, não é "pessoalmente" nada daquilo que ele é interiormente e exteriormente, nada daquilo que é finito, mas o puro infinito de um Si livre, livre de seu ser como de todo ser. A singularidade pessoal é singularidade universal em virtude da negatividade infinita que é a sua, que é o próprio $\mathrm{Si}$, em virtude de "sua própria efetividade negativa em relação à realidade" (exatamente: seine gegen die Realität negative, nur sich abstrakt auf sich beziehende Wirklichkeit, $\mathbb{S}$ 34). A infinitude da pessoa é, portanto, a afirmação de um si, mas uma tal afirmação é, ela mesma, um saber de si: o Eu é um tal saber de si como o infinito. Só há uma pessoa na medida em que o infinito é por si, sabe de si e se afirma como o infinito. Ora, o modo dessa afirmação e desse saber de si é a negatividade infinita por meio da qual ele se afirma como "esteaqui" que não é aquele que ele é a cada vez num modo finito. A Observação do $\ 35$ dos Princípios insistirá sobre esse ponto: a pessoa é consciência de si, mas consciência de si precisamente em sua abstração pura, e uma tal pureza só se atesta pela negação ativa de toda determinidade, de toda Besdränktheit. Ele não passa de um puro Si vazio: sua infinidade é também a pura identidade consigo, que sabe de si "como objeto elevado pelo pensamento à infinitude simples" (HEGEL, 1998, J 35 , p. 126). A personalidade emerge do puro pensamento de um Si que se sabe como além de tudo o que ele é enquanto permanece ainda finito. Consciência de si, mas que já não é simplesmente consciência do desejo e da "vontade natural", como Hegel explica nessa passagem. A consciência de si pessoal é aquela que pressupõe a vinda a si do pensamento puro, daquilo que a Fenomenologia havia chamado a "essência pensante", que a consciência é a partir de então, consciência na qual são negados o traba- 


\section{4}

lho e o desejo, e que não pára de se retirar em sua pureza, em sua liberdade e, na mesma medida, em sua pura abstração, quando, como insistia Hegel, "o pensamento não tem por verdade senão o pensamento puro, e essa ve rdade não é preenchida pela vida" (HEGEL, 2004, p. 160). Se é assim, uma tal proairésis estóica não encontrará seu acabamento efetivamente pessoal a não ser quando tiver ganhado também, para além da necessária abstração das figuras próprias à consciência de si - que não existem num mundo, mas são antes, como as figuras da consciência e da razão, como a auto-análise interior do espírito, o único efetivo -, a densidade espiritual do sentido tal qual está-aí: é somente no espírito, precisamente ao final da Sittlichkeit [eticidade] grega que a "personalidade pura" surgirá no mundo. Ora, não causa espanto encontrar já no texto de 1807 os traços que caracterizarão o conceito hegeliano de pessoa, tais quais valerão para a Idéia absoluta e para a "personalidade pura" que é o conceito: à unidade da vida ética, imediata, da singularidade e da substância, sucederá, como se sabe, a irrupção das singularidades atômicas que vivem então para si, as Selbstwesen, como escreve Hegel: "O Universal estilhaçado na atomicidade da pluralidade absoluta dos indivíduos, esse espírito agora morto é uma identidade na qual todos passam por pessoas, como sendo cada um"3. A verdade da Sittlichkeit acaba assim na pura certeza de si da singularidade abstrata, cuja efetividade é, com efeito, inteiramente negativa, ao assumir a necessidade destinal na qual a comunidade ética tragicamente se dissolve (pois o destino não é nada outro que o $I c h)$. O que resta, no final das contas, passando pelo próprio todo, é o Si "duro e áspero" (dieses spröde Selbst), a personalidade, como Selbständigkeit, subsistência por si da consciência. Hegel não deixa, então, para descrevê-la, de relembrar a abstração da consciência de si estóica, não sem assinalar, entretanto, que esta se tornou, desde então, um mundo, "mundo efetivo". Esse mundo é o mundo do direito, o mundo da "autonomia pessoal", que outra coisa não é senão "essa mesma desordem universal e essa dissolução recíproca" " que já caracterizavam a confusão cética engendrada pela ativação da abstração estóica, mediante a negação de toda certeza e de toda verdade. Que o mundo do direito seja ao mesmo tempo o da Verwirrung, da confusão, não surpreenderá aquele que se lembre que ele é antes de tudo, para Hegel, o mundo sem espírito, o mundo da unicidade vazia da pessoa, no qual todo conteúdo, sob o 
império de um tal formalismo mortal, é abandonado à sua liberdade mais selvagem, mais desordenada: "O espírito que o submetia e o continha na sua unidade já não está mais presente” (HEGEL, 2004, p. 327). O que permanece, é aquilo que o ceticismo - figura na qual a consciência de si já se tinha inteiramente fechado num Si que não era mais que o centro, o foco de uma negatividade infinita -, havia reputado como pura aparência, aquilo, no entanto, que agora se encontra invertido e assumido positivamente: "Esse valor positivo no direito consiste nisto, que o efetivo é o Meu no sentido da categoria, como validade reconhecida e efetiva". (HEGEL, 1998, p. 327; HEGEL, 2004, tradução modificada, p. 318). Que a pessoa seja o suporte da propriedade é também a dedução que é feita nos Princípios, quando eles apresentarão a personalidade como a base ela mesma abstrata (abstrakte Grundlage) da capacidade jurídica (Rechtsfähigkeit) e, por conseguinte, de todo o direito abstrato (\$ 36). A Fenomenologia já ressaltava a pura abstração do Meu, universal indiferente a seu conteúdo (não somente exterior, mas também interior, enquanto caráter), que é, por conseguinte, o mais contingente. Tal contingência caracterizava também a estranheza de tal conteúdo diante da forma pura da personalidade, e o reino sem espírito do direito tinha por correlato político a dominação imperial de uma "potência universal" ou "efetividade absoluta" na qual a pessoa exacerbava a abstração de seu sentido. Surgia já outro rosto da personalidade pura ou, antes, daquilo que Hegel chamava então "a pessoa absoluta”:"Esse senhor do mundo”, escrevia,"é, portanto, a seus olhos a pessoa absoluta que engloba ao mesmo tempo em si toda existência, e para a consciência do qual não existe espírito mais elevado" (HEGEL, 1998, p. 319; HEGEL, 2004, p. 327-328). A solidão da dominação imperial na Pessoa absoluta é o cume da "rigidez", Sprödigkeit, que caracteriza da maneira mais expressiva o mundo sem mundo, o espírito sem espírito das pessoas para si por exclusão da "continuidade com outros", que se cumprirá na Entfremdung [alienação] total da cultura. Sprödigkeit diz exatamente o caráter abstratamente, formalmente ríspido da pessoa, sobre o qual a Fenomenologia de 1807 punha inegavelmente ênfase. Mas devemos permanecer nela? Decisivamente, tal Sprödigkeit não é o que retornará na personalidade pura da Idéia absoluta - que se encontra assim à maior distância da "pessoa absoluta" imperial! -, já que, muito pelo contrário, ela será o acolhimento absoluto, absolutamente 


\section{6}

espiritual, que não pára de restabelecer, enquanto reconciliação, a continuidade com o ser-outro! Eis por que se faz necessário aprofundar o conceito hegeliano de pessoa para compreender a absolutez de que ela já é - mas é tão-somente - o conceito.

Se, com efeito, a personalidade é mesmo a abstrakte Grundlage do direito, seu conceito, no entanto, não é apenas jurídico, nem o mais originariamente jurídico. A singularidade universal que a pessoa é - e é justamente por essa razão que ela já é o conceito do espírito absoluto - se distinguirá, não somente por sua abstração pura, mas pela simplicidade imediata que, segundo Hegel, conterá toda decisão, e isso mesmo a vontade príncipe do Estado efetivo, o Estado da liberdade: "A singularidade da pessoa, que é imediata e decide...", escreve Hegel no \39: noutras palavras, o que caracteriza a pessoa não é, seguramente, seu ser, mas a atividade primeiramente negativa de suprimir sua limitação subjetiva (exatamente: die Beschränkung, nur subjektiv zu sein,"a limitação de não ser senão subjetiva”) e, assim, sua relação negativa a si. Atividade: a própria pessoa é, mais precisamente ainda, das Tätige, aquilo cuja atividade, escreve Hegel, consiste em suprimir tal Beschränkung e em "se dar realidade" na apropriação, na posição, no Setzen do Dasein como sendo seu. Somente tal Einzelnheit da pessoa decide ou se resolve, somente ela é, no alemão de Hegel, beschliessend [decididora-decisiva]. Como pensar tal ato do beschliessen, que parece constituir aqui todo o sentido da atividade pessoal quando ela põe o Dasein como sendo o seu? Hegel comentou dire tamento o sentido do beschliessen, quando, na Introdução ao Princípios ele começa por desenvolver o conceito de vontade, ou seja, da liberdade que é o conceito ou a "substancialidade" da vontade (\$ 7). A vontade livre é a singularidade na qual a particularidade finita, "refletida no interior de si" é "reconduzida à universalidade", à identidade de um Si que, nela, resta todavia junto de si, um Si que, por conseguinte, em sua essência pessoal, "se põe como o negativo de si mesmo" (\$ 7 ). Dar-se assim a singularidade, ou a "forma da singularidade", eis o que quer dizer exatamente "decidir", beschliessen, suprimir a indeterminação dos conteúdos possíveis que estão aí diante do Si ou nele, dar-se realidade, ou melhor, efetividade: "É somente enquanto vontade que decide em geral que ela é vontade efetiva (nur als beschliessender Wille überhaupt ist er wirklicher Wille) (HEGEL, 1967, Introdução, p. 36; trad. 107). O Si retirará toda a sua efetividade da 
decisão em que ele se põe como singularidade pessoal, e Hegel afirma muito precisamente que o sentido dessa decisão, desse beschliessen, é o da negatividade: "Suprimir o indeterminado no qual tanto um conteúdo quanto o outro é, antes de mais nada, apenas um conteúdo possível" (HEGEL, 1967, Introdução, p. 36; trad. 107) eis o que é a decisão da singularidade como unidade da particularidade e da universalidade. Mas Hegel quer também se precaver de uma interpretação da vontade, da vontade ao menos tomada em seu conceito acabado, como sendo pura potência de escolher entre os conteúdos que ela própria não teria criado, potência de eleger aquilo que se encontraria assim originariamente fora dela e que ela encontraria ali, diante dela, o que será o conceito, apenas intermediário, de arbítrio. A vontade efetiva será, muito pelo contrário, criadora daquilo que ela põe, e a decisão não é somente aquilo que produziria a passagem da esfera dos conteúdos possíveis àquela dos fins realmente postos, mediante escolha no reino substancial dos possíveis. A vontade decisiva será, na verdade, a vontade que se resolve sempre a partir de si, e o Beschliessen, precisa a Observação do $\int 12$, é em sua verdade aquilo que o alemão chama de um sich entschliessen, um "se resolver" a partir de si, separando-se de si, cindindo-se de si, como seria possível, não traduzir, mas compreender essa outra expressão, sobre a qual Hegel, por sua vez, tem o cuidado de se explicar: decidir consiste em se resolver “... na medida em que a indeterminidade da própria vontade, enquanto elemento neutro, mas fecundado infinitamente, germe originário de todo ser-aí, contém em si as determinações e os fins e não os produz senão a partir de si” (HEGEL, 1967, Observação). A decisão, que, é certo, tomará primeiro uma forma ainda inteiramente reflexiva, não é todavia apenas escolha, mas criação a partir de si, autodeterminação ou autodiferenciação de uma vontade que em sua decisão se põe como singularidade pessoal, isto é, pode sempre se decidir também pela finitude, como o nota Hegel na Observação do $\ 13$. A infinidade formal da pessoa ligar-se-á assim por si mesma a um conteúdo finito, que em sua exterioridade em relação a ela se dará primeiro na contingência da submissão ao arbítrio, que, por conseguinte, ainda não é ele próprio a vontade liv re, acabada enquanto vontade, mas sim, conforme a Observação do $\ 15$, "a vontade como contradição, determinação da reflexão na qual a infinitude da forma é suprimida pela finitude e contingência do conteúdo. Só a 


\section{8}

vontade que é pensada, que se sabe e se quer ela mesma, é infinita, ela será o "efetivamente infinito" $(\$ 22)$. O primeiro momento de uma tal vontade infinita será a personalidade, na qual a vontade coincidirá com o pensamento. A personalidade é portanto essencialmente pensamento de si, saber de si em sua infinidade. A singularidade pessoal, que encontra diante de si uma natureza à qual ela, enquanto o subjetivo, se opõe, suprime a cada momento essa limitação subjetiva, ao se realizar na apropriação do ser-aí, como esfera exterior da liberdade, no contrato que liga as pessoas e na negação (penal) dessa negação do direito que é a "recusa do que é direito" (das Unrecht). Tal efetuação da liberdade não se restringe certamente à pessoa, que não passa de seu jorro objetivo inicial. Entretanto, para o propósito que buscamos agora é de capital importância ressaltar que, com a pessoa, começa, na simplicidade de sua expressão imediata, a identidade da vontade e da inteligência, que ainda estavam cindidas no espírito subjetivo: a personalidade já é, portanto, neste sentido, o conceito do espírito absoluto no qual a universalidade racional se consuma como decisão singular, em virtude da qual ela não é - ou, antes, não é somente - substância racional (o saber absoluto não é somente substancial), mas plenamente Sujeito. Mas se, em sua extremidade mais fina, o coração da personalidade é a decisão da Singularidade, como pensar, na Lógica, a decisão da personalidade pura que é a Idéia absoluta? Qual é a decisão do conceito? Qual é o sujeito do sistema?

Para concluir é preciso voltar à decisão, absolutamente pessoal, que é como o ato inicial e final do sistema ou, antes, o próprio sistema enquanto atividade afirmativa ou, melhor dizendo, especulativa da Idéia ${ }^{5}$. Tal decisão absolutamente nada retirará à necessidade, à unive rsalidade do conceito, sustentada justamente pela negatividade dialética. Tal decisão, por conseguinte, nada retirará à ciência dialética enquanto ciência. Ela pretenderá dizer, no entanto, que a verdade de tal necessidade está na liberdade de um ato absoluto, ato de afirmação de si da Idéia absoluta, de afirmação de si do sentido, mediante decisão do sujeito finito. A verdade em que a Idéia consiste é a subjetividade em sua simplicidade impenetrável, indivisível, sem dúvida, mas - "da mesma maneira" - simplicidade em sua racionalidade acolhedora do seu outro ou de um objeto que é desde então o seu, ela mesma fazendo de si objeto para si mesma: o ser-outro não é menos seu, com efeito, do que o si é ele próprio objeto para si mesmo. Mas 
então abramos de novo, no mesmo lugar, a Doutrina do Conceito. Se a Idéia lógica era de início, ou unilateralmente teórica, ou unilateralmente prática, somente ein gesuchtes Jenseits und unerr e i chtetes Ziel (HEGEL, 1994, p. 283, trad., p. 367) (e assim somente um Streben, comenta Hegel), alcançando a absolutez plenamente racional, ela retorna à imediatez simples da vida. Ela é, no entanto, retorno à imediatez, Rückkehr zum Leben, que ela havia antes suprimido, tendo desde agora em si - como conquista da negatividade - “ a mais alta oposição”. Assim, a Idéia é, em sua imediatez, o Si da Pessoa, a subjetividade pessoal "atômica", "impenetrável" - mas devemos então prestar bastante atenção a uma das palavras mais discretamente decisivas em Hegel, talvez a palavra especulativa por excelência:“der Begriff ist nicht nur Seele, sondern freier, subjektiver Begriff, der für sich ist und daher die Persönnlichkeit hat-der praktische, an und für sich bestimmte, objektive Begriff, der als Person undurchdringliche, atome Subjektitität ist"... Ao que se segue: "der aber ebensosehr nidt ausschliessende Einzelheit, sondern für sich Allgemeinheit und Erkennen ist und in seinem Anderen seine eigne Objektivität zum Gegenstand hat" (HEGEL, 1994, p. 284, trad. p. 368). Tanto aqui quanto antes ${ }^{6}$, esse ebensosehr é capital. Ele faz lembrar que o conceito é, por certo, personalidade, mas personalidade racional, singularidade universal, que não poderia ser confundida com a personalidade absoluta imperial, a singularidade violenta. Não há, rigorosamente, "imperialismo" do conceito no sistema hegeliano, o qual, assim, nunca é um método que não seja umsistema, que não se alargue de si mesmo num sistema - tampouco quanto é possível admitir uma impessoalidade da Idéia hegeliana, como foi pensada e combatida por Kierkegaard -, pois a personalidade pura de maneira alguma é o reino dominador do Sentido sobre o contra-senso, reino do direito no qual, todavia, é a separação não espiritual que prevalece. Uma tal unificação dominadora seria antes nela mesma o reino do contra-senso, do caos, da "violência destruidora" do imperial, ela significaria a morte do espírito na ausência de substancialidade (Substanzlosigkeit) da personalidade jurídica e da personalidade absoluta imperial que lhe faz frente, sem a menor continuidade espiritual de uma pessoa a outra. Nessa medida, eis aquilo que, no próprio texto da Fenomenologia, não é o conceito, a personalidade definitivamente superada nele: "Diante disso, a erosão avassaladora desse solo sem essência se dá a consciência de seu total domínio sobre todas as coisas, mas esse Si-mesmo não é senão devastação e, portan- 
to, ele está somente fora de si; ele é, antes, propriamente a rejeição de sua consciência de si" (HEGEL, 1998, p. 319; trad., pp. 328-329). O espírito tem em si mesmo sua própria negação, sua própria contradição, o Sentido em verdade espiritual tem nele a morte espiritual do sentido, e ele se ave ntura totalmente nessa Entfremdung que, no plano objetivo, se chama cultura. A personalidade pura é a consciência de si acabada, que, no acolhimento racional do ser-outro, suplantou aquela rejeição, das Wegwerfen, na qual ela rejeitava para o fundo, quebrando a continuidade com o ser-outro, sua própria consciência de si. A reconciliação sempre tem nela a mais dura rejeição, como sendo aquilo que precisamente ela suplantou. A morte está no espírito, como morte suplantada, vida que suplantou a oposição entre vida e morte, oposição que ela traz agora em si.A verdade é subjetividade, mas a subjetividade espiritual tem em si o extremo da subjetividade violenta, o Para-Si absoluto que vai até sua própria negação, como risco que ela admite intimamente, risco retomado e curado nela. A personalidade pura é a personalidade curada de sua própria rejeição de si mesma por si mesma. A dominação, Herrschaft, terá então cedido diante da serenidade de uma razão que concede existência a um outro que ela sabe ser o seu, que ela sabe ser seu objeto, a sua objetividade para si mesma de si mesma: Gelassenheit.A impenetrabilidade da subjetividade faz parte da Idéia, em sua afirmação de si, em sua decisão de si. Mas a subjetividade não é nada, ela é puro nada, o puro Nada do sujeito que nadifica todas as coisas, de que há tantas figuras em Hegel, quando ela não sabe se dar, se abandonar - ebensosehr - à substancialidade da Coisa mesma: abandonar-se assim à Coisa, é o caminho do conhecer, caminho da unive rsalidade do sentido, da personalidade absolutamente racional: "Alles übrige ist Irrtum, Trübheit, Meinung, Streben, Willkür und Vergänglidhkeit' (HEGEL, 1994, p. 284, trad., p. 368). O mais verdadeiro sentido da unive rsalidade do método, escreverá mais adiante Hegel, consiste num mesmo ebensosehr ou, exatamente, num sowohl,segundo o qual ela não é somente "die A rt und Weise des Erkennens", mas - "igualmente"-“die objektive A it und Weise oder vielmehr die Substantialität der Dinge” (HEGEL, 1994, p. 287; trad., p. 371). A pers o n a lidade, a atividade do conceito, "atividade unive rsal absoluta", não é subjetividade senão na medida em que ela é "igualmente" substancialidade. Entretanto, ela não é nem uma, nem outra, o mais objetivo e o mais subjetivo, a não ser em virtude do Wendungspunkt que é a negatividade. Por 
meio desta se considera antes de tudo a relação negativa a si, der innerste Quell aller Tätigkeit (HEGEL, 1994, p. 296; trad. p. 382), que é a subjetiv idade e, além dessa relação, a relação negativa a si do negativo ele mesmo, o mais íntimo da vida do espírito, escreve Hegel, a subjetividade pessoal. À contradição da passagem de um a seu outro, primeira premissa do silogismo total, sucede a relação do negativo a si mesmo, a negação de si da contradição, segunda premissa do silogismo especulativo: tal é o momento rigorosamente subjetivo deste, o acabamento da unidade pela negatividade como mediação absoluta, em virtude da qual se estabelece imediatamente a imediatez inicial (Herstellung, escreve Hegel: a imediatez aparentemente inicial é, na verdade, o que é estabelecido). Esse momento último, terceiro ou quarto dependendo da conta, é subjetividade enquanto atividade ou movimento, "atividade que se medeia consigo mesma", que é, para o sujeito, sich zum Freisten machen, um "fazer de si o mais liv re". Essa atividade, de "estabelecer" o imediato ou o início, de "se conservar" (sich erhalten) para o conceito no seu ser-outro, de se tornar o mais livre, é, nela mesma, condensação, sich verdidten (HEGEL, 1994, p. 302; trad., p. 388) ou intensificação. $\mathrm{O}$ momento da personalidade designa bem exatamente então essa condensação ou intensificação por meio da qual a ampliação, Erweiterung,que é a primeira premissa (comunicação, Mitteilung, do unive rsal ao conteúdo, escreve Hegel), ir-fora-de-si (passagem ao seu outro) é então dialética, segunda premiss, relação negativa a si, ir-em-si. A extensão, Ausdehnung, é intensificação de si. Podemos então reencontrar a personalidade pura com a qual havíamos começado: "O mais rico é assim o mais concreto e o mais subjetivo, e aquilo que se retoma na profundeza mais simples é o mais potente e o que mais longe se propaga (das Mächtigste und Übergreifendste)(HEGEL, 1994, p. 302; trad. pp. 388-389). No final da Ciência da Lógica, o sujeito absoluto é alcançado, aquele cuja decisão de sair de si - decisão de sua plenitude e não de sua falta, transbordmento de si e não aflição de seu outro, liberdde que dá e que de nada se apropria -, rompendo sua barreira, abandonará a natureza, a fim de abrir o segundo círculo do sistema. Mas aquilo que se alcança com a personalidade pura do conceito é "igualmente" o ser, o começo, o ser desde agora o mais intenso, o começo "estabelecido" enquanto começo. A personalidade pura não vem senão no fim, como verdadeiro começo do sistema - seu ômega, mas, eben so sehr, seu alfa. 
${ }^{1}$ HEGEL 1994, Die Lehre vom Begriff, pp. 302-303. Conferir a tradução de Gw. Jarczyck e P.J. Labarrière (1981). Nós retraduziremos os textos, por vezes segundo outras decisões, mas remeteremos também a essa tradução.

2 “A verdade é a subjetividade” (KIERKEGAARD, 1977, pp. 176 e segs.).

3 HEGEL, 1998, p. 316; tradução, p. 325. "Das Allgemeine in die Atome der absolut vielen Individuen zersplittert, dieser gestorbene Geist ist eine Gleichheit, worin Alle als Jede, als Personen, gelten."

4 "Diese gleiche allgemeine Verwimung und gegenseitige Auflösung” (HEGEL, 1998, trad., p. 317). Verwirrung é a palavra já aplicada ao ceticismo e à sua "tagarelice".

5 Cf. HEGEL, 1986, Conceito Preliminar $₫ 16$ (1817) e $₫ 82$ (1827-1830), p. 344:“'O especulativo ou positivamente racional apreende a unidade das determinações em sua oposição, o afirmativo que está contido na resolução delas e em sua passagem (a outra coisa". O especulativo, diz o Adendo do professor berlinense, nada mais é que o racional pensado, aquilo que detém em si as contradições "como suprimidas", ou seja, ele nada mais é que o concreto! É, da mesma maneira, o místico, que não tem então nada de inconcebível. $\mathrm{O}$ ato especulativo é o ato afirmativo por excelência, a afirmação mais alta, cujo caminho não poder ser senão a negatividade absoluta, somente por meio da qual há um Sujeito.

6 "...ds Wahre nicht als Substanz, sondern eben so sehr als Subjekt aufzufassen und ausdrücken" HEGEL 1998, Prefácio, p. 14. O grifo da expressão é nosso, nos dois casos.

\section{Referências bibliográficas}

HEGEL 1967. Princípios da Filosofia do Direito. Hamburgo: Meiner. Tradução de J.-Fr. Kervégan. Paris: Puf, 1998.

HEGEL 1968. Enciclopédia das Ciências Filosóficas. Tradução de Bernard Bourgeois. Paris:Vrin.

HEGEL 1986. Enciclopédia. Conceito preliminar. Tradução de Bernard Bourgeois. Paris:Vrin.

HEGEL 1994. Ciência da Lógica. Hamburgo: Meiner. Tradução de GW. Jarczyck e P.-J. Labarrière. Paris: Aubier-Montaige.

HEGEL 1998. Fenomenologia do Espírito. Hamburgo: Meiner. Tradução de J.P. Lefebvre. Paris: Aubier-Flamarion, 2004.

KIERKEGAARD, S. 1977. Post-scriptum définitif et non-scientifique aux Miettes philosophiques (1846). Tradução de P.H. Tisseau. Paris: Orante, vol. 10. 